\title{
Demographic Characteristics of the Population Undergoing Cine Coronary Angiography at the Instituto do Coração of the Medical School of USP from 1986 to 1995
}

\author{
Bruno Caramelli, Luciana Savoy Fornari, Maristela Monachini, Dália Ballas, N ilson Roberto Fachini, \\ Antônio de Pádua Mansur, José Antônio Franchini Ramires
}

São Paulo, SP - Brazil

\begin{abstract}
Objective - To obtain information about the profile and behavior of a population with ischemic heart disease undergoing cine coronary angiography and to determine disease severity.
\end{abstract}

Methods - Retrospective study assessing patients hospitalized at InCor from 1986 to 1995, in which the variables age, sex, and number of major coronary arteries with obstruction degree $\geq 40 \%$ were analyzed.

Results - We studied 18,221 patients and observed a significant increase in the number of females $(22.8 \%$ to $25.2 \%, P=0.001)$ and an increase in age (57.1 \pm 29.3 to $60.4 \pm 10.7$ years, $P=0.0001)$. A significant increase in the incidence of multivessel disease was observed, which was more frequent among males (69.2\% and 64.5\%) and among the older patients (59.8 \pm 9.8 and $56.8 \pm 10.7$ years, $P=0.0001)$. A reduction in the incidence of single-vessel disease was also observed (66.2\% vs $69.2 \%$ and $33.8 \%$ vs $30.5 \%$, respectively, $P<0.0001)$.

Conclusion - A change in the profile of the population studied was observed as follows: patients undergoing cine coronary angiography at InCor were older, had a greater number of impaired major coronary arteries, and the number of females affected increased, leading to indices suggestive of a poorer prognosis.

Key words: acute myocardial infarction, coronary artery disease, cine coronary angiography.

Instituto do Coração of the Medical School of the Universidade de São Paulo (USP). Mailing address: Bruno Caramelli - InCor-Av. Dr. Enéas C. Aguiar 44 - 05403-000 - São Paulo, SP, Brazil - E-mail: bcaramel@incor.usp.br

English version by Stela Maris C. e Gandour
Recent studies have shown changes in the incidence of and in the mortality due to ischemic heart disease ${ }^{1,2}$.

In Brazil, similar results have been found with a reduction in the risk of death and an increase in the prevalence of ischemic heart disease in younger age groups ${ }^{3,4}$. These changes may modify the profile of the ill population, and, once the changes are identified, insights may be gained into improved prevention and treatment of ischemic heart disease.

Cine coronary angiography provides major information for characterizing the profile of patients with ischemic heart disease. Patterns of the severity of the disease, as well as the strategies of patient management and treatment, have been established based on cine coronary angiography ${ }^{5}$.

However, no information about the clinical and angiographic characteristics of a certain Brazilian population diagnosed with ischemic heart disease undergoing cine coronary angiography exists. We believe that knowing data about the population affected by the disease is important because they reflect the spectrum of one of the major causes of mortality in our country with great implications for the Brazilian Public Health System (Sistema Único de Saúde), in addition to providing knowledge about our national circumstances.

This study aimed at determining the demographic characteristics of the population undergoing cine coronary angiography at InCor of the Medical School of the University of São Paulo, and the severity of ischemic heart disease in that population.

\section{Methods}

The patients undergoing cine coronary angiography at InCor from 1986 to 1995 were retrospectively assessed. Patients younger than 20 years and those who did not have significant obstructions of at least 1 major epicardial coronary artery were excluded from the study. 
The variables analyzed were age, sex, and the number of major coronary arteries with a degree of obstruction $\geq$ $40 \%$, which classified the disease as single- or multivessel ${ }^{6}$. Information was obtained from the reports of the databank that compiles the examinations performed by the hemodynamics laboratory at InCor.

The variables, such as the number of arteries with significant obstruction, were analyzed in their absolute and relative frequencies. An initial exploratory analysis allowed a division into 2 periods according to the years in which modifications in frequencies were observed (1986-1990 and 1991-1995). The proportions were compared with the chisquare test to discriminate the differences between the periods. Age, a continuous variable, was analyzed in regard to the means, standard deviations, minimum and maximum values. The means were compared with the Student $t$ test. The significance level adopted was 0.05 .

\section{Results}

The study comprised 18,221 patients. The division by periods is shown in figure 1 , where a significant increase in the frequency of female patients is seen from the 1986-1990 period to the $1991-1995$ period $(\mathrm{P}=0.001)$.

A significant increase in the age of the patients from the 1986-1990 period (57.8 years) to the 1991-1995 period (59.9 years, $\mathrm{P}=0.0001$ ) occurred (fig. 2 ).

The analysis of the relation between the variables age and sex revealed that females were older than males $(61.3 \pm$ 10 vs. $58.1 \pm 10.2$ years, $\mathrm{P}=0.0001$ ).

In regard to the number of major arteries with an obstruction degree $\geq 40 \%$, a significant increase in the incidence of multivessel disease was observed from 1986-1990 to 1991-1995 ( $\mathrm{P}<0.0001$ )(fig. 3). Multivessel disease was more frequent among males $(69.2 \%$ vs. $64.5 \%, \mathrm{P}=0.0001)$, while single-vessel disease was more frequent among females ( $35.5 \%$ vs. $30.8 \%, \mathrm{P}=0.0001)$. The analysis of the relation between the variables obstruction greater than $40 \%$ and age revealed that a significant difference in age exists, patients with multivessel disease being older than those with single-vessel disease ( 59.8 vs. 56.8 years, $\mathrm{P}=0.0001$ ).

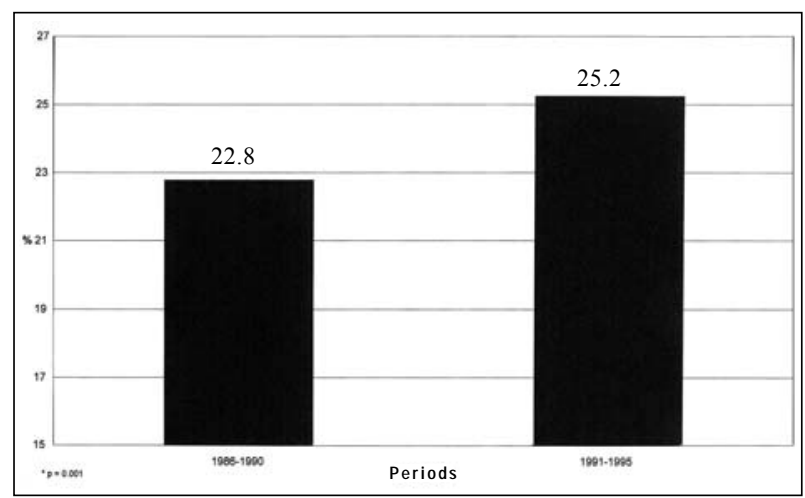

Fig. 1 - Relative frequency of women in the different periods.

\section{Discussion}

This study showed a significant increase in age, in the frequency of female patients, and in the frequency of multivessel obstructions among patients undergoing cine coronary angiography. In addition, it showed that multivessel disease is more frequent in male patients, while single-vessel disease is more frequent in female patients, and confirmed the findings of previous studies, in which females with ischemic heart disease were older than males with the same disease ${ }^{6-8}$.

The behavior of the population undergoing cine coronary angiography in our study was similar to that of the populations with the acute and chronic forms of the disease, stressing the idea that significant changes are actually occurring in the characteristics of the population diagnosed with ischemic heart disease treated at InCor ${ }^{9}$.

In an observational longitudinal study with $5,117 \mathrm{pa}-$ tients carried out by Roger et al ${ }^{10}$ in Minnesota, between the years 1979 and 1994, similarly to our study's findings, the incidence of acute myocardial infarction decreased in males,

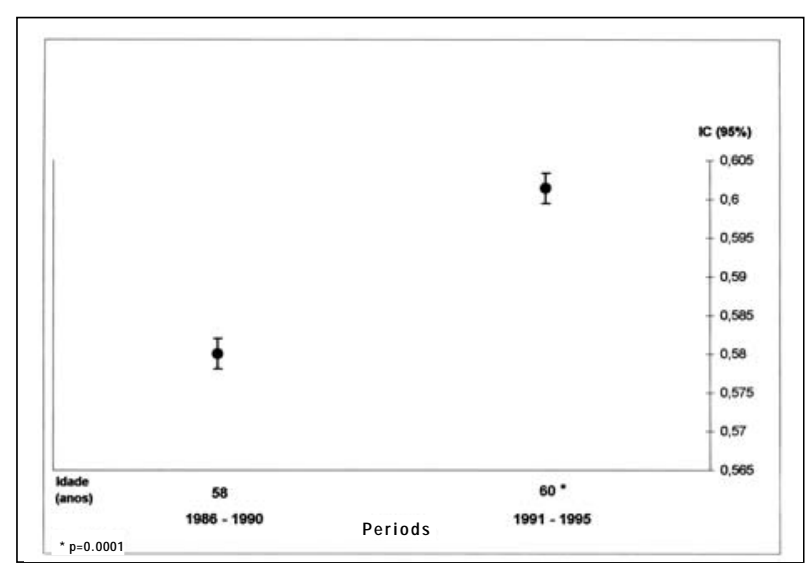

Fig. 2-Mean age and confidence intevals of the different periods.

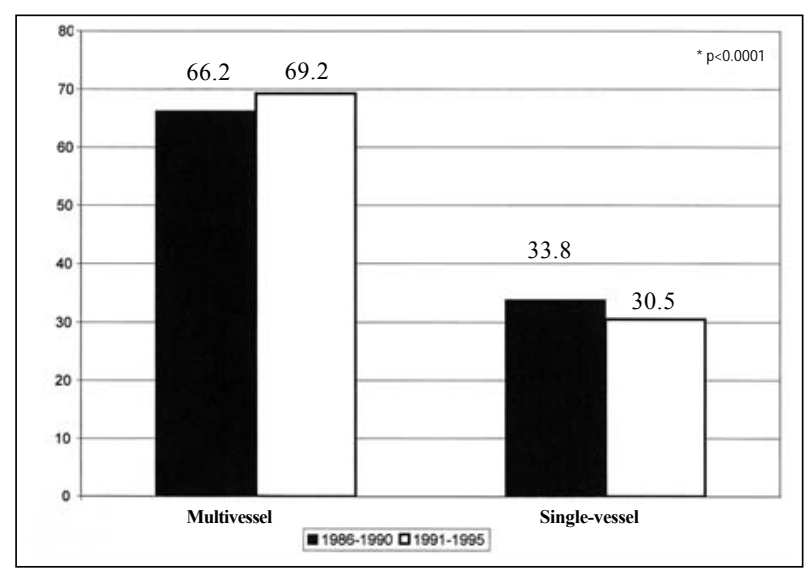

Fig. 3 - Relative frequency of multivessel and single-vessel patients in different periods. 
but increased in females and in the elderly. In the same period, however, the incidence of acute myocardial infarction adjusted for age decreased by $8 \%$ in males (CI, $23 \%$ to $10 \%$ ) and increased by $36 \%$ in females (CI, $9 \%$ to $70 \%$ ). Likewise, a $31 \%$ decrease in the incidence of acute myocardial infarction was observed over the years in males $<40$ years of age, and a $49 \%$ increase in females $>80$ years. These data suggest the occurrence of a change in the profile of the population with ischemic heart disease in the United States, with a higher prevalence in females and in the elderly.

The findings in our study can be explained by the changes in the demographic characteristics, ie, the population aging caused by the increase in life expectancy and deri- ved from the reduction in mortality due to ischemic heart disease ${ }^{3-11,12}$. Therefore, older patients more often have multivessel disease. The greater incidence of single-vessel disease in females, although they are older, can be explained by the fact that they have the disease at a more advanced age, because the natural history of ischemic heart disease among females begins later.

In conclusion, this study suggests a change in the profile of the population with ischemic heart disease treated at InCor as follows: the patients are older, a greater number of major coronary arteries are affected, and the incidence among females has increased, all of which are indices suggestive of a poorer prognosis.

\section{References}

1. Naylor CD, Chen E. Population-wide mortality trends among patients hospitalized for acute myocardial infarction: the Ontario experience, 1981 to 1991. J Am Coll Cardiol 1994; 24:1431-8

2. Gillum RF. Trends in acute myocardial infarction and coronary heart disease death in the United States. Am J Cardiol 1994; 23: 1273-7,.

3. Lotufo PA, Lolio CA. Tendência da mortalidade por doença isquêmica do coração no estado de São Paulo: 1970 a 1989. Arq Bras Cardiol 1993; 61: 149-53.

4. MansurAP, Souza MF, TimermannA, Ramires JA. Tendência do risco de morte por doenças circulatórias, cerebrovasculares e isquêmicas do coração em 11 capitais do Brasil de 1980 a 1998. Arq Bras Cardiol 2002; 79: 269-76.

5. CASS Principal Investigators and their Associates. Coronary Artery Surgery Study (CASS): a randomized trial of coronary artery bypass surgery: Survival data. Circulation 1983; 68:939-50.

6. ISIS-2 (Second International Study of Infarction Survival) Collaborative Group. Randomised trial of intravenous streptokinase, oral aspirin, both, or neither among 17, 187 cases of suspected acute myocardial infarction: ISIS-2. Lancet 1988; 2:349-60.
7. Gruppo Italiano Per lo Studio Della Streptochinasi Nell' Infarto Miocardico (GISSI). Effectiveness of intravenous thrombolytic treatment in acute myocardial infarction. Lancet 1986; 1:397-401.

8. Roberts R, Morris D, Pratt CM, Alexander RW. Pathophysiology recognition and treatment of acute myocardial infarction and its complications. In: Schlant RC, Alexander W. Hurst's The Heart: Arteries and Veins. New York: Ed. McGraw-Hill. Inc, 1994:1107-85.

9. Caramelli B. Tendências seculares da população com doença isquêmica do coração internada em hospital especializado. Tese (livre-docência) Faculdade de Medicina da Universidade de São Paulo. Departamento de Cardio-Pneumologia. Disciplina de Cardiologia. São Paulo, 1997.

10. Roger VL, Jacobsen BJ, Wessinon BA. Trends in the incidence and survival of patients with hospitalized myocardial infarction, Olmsted County, Minnesota, 1979 to 1994. Ann Intern Med 2002; 136(suppl V): I16.

11. The University of Chicago. Population. In: Enciclopedia Britannica. $15^{\text {a }}$ ed. Chicago: Ed. Encyclopedia Britannica. Inc, 1991; 25: 1034-43.

12. Leser W, Barbosa V, Baruzzi RG, Ribeiro MBD, Franco J. Elementos de Epidemiologia Geral. Rio de Janeiro/São Paulo: Livraria Atheneu, 1988: 177. 